\title{
Study of Etiological Profile, Clinical Profile and Short Term Outcome of Patients Presenting with Pericardial Effusion in a Tertiary Care Center, Nepal
}

\author{
Raja Ram Khanal*, Ratna Mani Gajurel, Ravi Sahi, Hemant Shrestha, Chandra Mani Poudel, \\ Surya Devkota, Sanjeev Thapa, Smriti Shakya \\ Department of Cardiology, Manmohan Cardio Thoracic Vascular and Transplant Centre (MCVTC), Institute of Medicine, \\ TUTH, Kathmandu, Nepal \\ Email: *khanalr82@gmail.com
}

How to cite this paper: Khanal, R.R., Gajurel, R.M., Sahi, R., Shrestha, H., Poudel, C.M., Devkota, S., Thapa, S. and Shakya, S. (2019) Study of Etiological Profile, Clinical Profile and Short Term Outcome of Patients Presenting with Pericardial Effusion in a Tertiary Care Center, Nepal. World Journal of Cardiovascular Diseases, 9, 879-890. https://doi.org/10.4236/wjcd.2019.912078

Received: June 10, 2019

Accepted: December 10, 2019

Published: December 13, 2019

Copyright $\odot 2019$ by author(s) and Scientific Research Publishing Inc. This work is licensed under the Creative Commons Attribution International License (CC BY 4.0).

http://creativecommons.org/licenses/by/4.0/

\begin{abstract}
Introduction: Pericardial effusion is one of the common cardiac problems in our part of the world and adds burden to the health and economy of the country, as it is associated with high risk of morbidity and mortality. Our objective of the study was to determine the etiological spectrum of pericardial effusion, their clinical presentations and complications and assessing the usefulness of echocardiographic features of effusion in helping to determine the etiology. Methods: A cross-sectional observational prospective study of 63 patients with diagnosis of pericardial effusion was enrolled in the study. Pericardial effusion was diagnosed by echocardiography and pericardiocentesis was done in the cardiac catheterization room. Patients were followed up 3 monthly for 1 year and reassessed clinically and by echocardiography. Results: Patients presenting with pericardial effusion belonged to the age group of 8 to 88 years. The most common etiology was tuberculosis (36.5\%) followed by malignancy (19\%) and idiopathic/Viral (12.6\%). Among malignancies, carcinoma lung was the most common cause followed by lymphoma. Pericardiocentesis was done in 46 patients $(73 \%)$ and the approach was subxiphoid. The procedure-related complications were in 4 patients $(6.3 \%)$ and there was no death as a consequence of the procedure. The total mortality was 12 (19\%) with in-hospital death of 6 patients (9.5\%). Conclusions: The study showed tuberculosis as the most common cause of pericardial effusion in developing countries like Nepal and as a cause of cardiac tamponade in contrast to the studies from the developed world where malignancy remains the leading cause.
\end{abstract}




\section{Keywords}

Malignancy, Pericardial Effusion, Pericardiocentesis, Tuberculosis

\section{Introduction}

The pericardium is a double-walled sac composed of two different layers an outer fibrous parietal pericardium and an inner visceral pericardium. The inner visceral pericardium is a serious type of membrane and is located immediately outside of the myocardium.

Pericardial cavity which is in between the parietal and visceral pericardium is filled with $10-50 \mathrm{cc}$ of fluid an ultra filtrate of plasma that is produced by the visceral pericardium. Pericardial fluid acts as a lubricant between the heart and the pericardium. Pericardial effusion is termed when there is excess fluid or blood accumulation in the pericardial cavity [1].

Pericardial effusion can develop in patients with any condition that affects the pericardium including acute pericarditis and a variety of systemic disorders. The effusion may or may not be associated with pericarditis. The etiology of pericardial effusion has changed over time and varies depending on geography and the population [2].

There is diversity in clinical etiology of pericardial effusion which includes malignancies of other organs, pulmonary tuberculosis, chronic renal failure, thyroid disease, autoimmune disease, iatrogenic and idiopathic.

The development of a pericardial effusion may have important implications for the prognosis (as in patients with intra thoracic malignancy) or diagnosis (as in myopericarditis or acute pericarditis) or both (as in dissection of the ascending aorta).

When a pericardial effusion is initially or incidentally detected, a major concern for clinicians may be its etiology. In a majority of cases, the etiology of the effusion can be presumed from the underlying condition of the patient. Pericardiocentesis is only indicated when the effusion is large or symptomatic, the effusion is accompanied by tamponade or the cause of the effusion is questionable [3].

\section{Methods}

A cross-sectional observational prospective study was done at Manmohan Cardio thoracic Vascular and Transplant center (MCVTC), a tertiary care centre.

63 patients were evaluated at our hospital, over a period of one year.

Iatrogenic (cardiac surgery, catheterization) and post traumatic cases were excluded.

Data were collected including history, general and full cardiovascular assessments. Investigations included electrocardiogram, chest roentgenogram and echocardiography for all patients. The inclusion and exclusion criteria were as follows. 


\section{Inclusion Criteria}

Moderate to large pericardial effusion with and without cardiac tamponade.

Mild or loculated pericardial effusion with tamponade.

\section{Exclusion Criteria}

Iatrogenic/post traumatic pericardial effusion.

Mild pericardial effusion $<10 \mathrm{~mm}$ in absence of cardiac tamponade.

Anasarca due to CHF, Hypoproteinemia.

Patients not giving consent.

The diagnosis of pericardial effusion was established by echocardiography, seen as echo-free space surrounding the heart.

The size of the Effusion was categorized by measuring the fluid strip as small when it is less than $10 \mathrm{~mm}$, moderate-sized when it is 10 to $20 \mathrm{~mm}$ and large when it is more than $20 \mathrm{~mm}$. Effusion measuring less than $10 \mathrm{~mm}$ in absence of tamponade was not included. Tamponade was defined as early diastolic right atrial and/or ventricular collapse or more than $25 \%$ change in mitral inflow velocities with respiration in presence of tachycardia, hypotension or significant paradox [4].

Evaluation for the cause of PE included complete blood count with ESR, Blood urea, serum creatinine, tuberculin skin test, Chest X-ray, Quanti FERON TB-GOLD (interferon- $\gamma$ release assay used for diagnosis of tuberculosis), Thyroid profile, ANA, Rheumatoid factor, CT chest/MRI and pericardiocentesis.

Pericardial fluid was analysed for cells, proteins, $\mathrm{LDH}$, malignant cells, ADA, PCR (for mycobacterium tuberculosis), gram staining, AFB staining and cultures.

Final diagnosis was based on clinical history, examination, and specific laboratory investigations for tuberculosis, uraemia, malignancy, collagen vascular disease hypothyroidism, etc. The diagnosis of acute idiopathic/viral etiology was presumptive and was based on the clinical picture, and negative screening tests for other etiologies.

Therapeutic Echo-guided percutenaous pericardiocentesis was performed by placing pigtail catheter in pericardial space through subxiphoid approach.

\section{Follow up}

All patients were followed up after 1 month and then three monthly for one year.

The study was approved by our own institutional ethics committee and signed informed consent was taken from all patients before enrolment in this study.

\section{Results}

The study included 63 patients with age ranging from 8 to 88 years. 26 patients (41.2 percent) were female and 37 (58.7 percent) were male.

The most common clinical feature was shortness of breath (95\%) followed by tachycardia (63.4\%). The least common clinical feature was palpitation (3\%) (Table 1). 
Out of 63 patients, 10 patients $(15.8 \%)$ presented with moderate pericardial effusion; 53 patients (84\%) presented with large pericardial effusion.

A total of 40 patients (63\%) had echocardiographic as well as clinical evidence of cardiac tamponade (Table 1).

There was no any patient with mild/loculated effusion with tamponade.

The most common etiology of pericardial effusion was tuberculosis $(n=23$; $36.5 \%)$ followed by malignancy $(\mathrm{n}=12 ; 19 \%)$, acute idiopathic/viral $(\mathrm{n}=8$; 12.6\%) (Table 2).

Among malignancies, carcinoma lung was the most common $(n=5)$, followed by lymphoma $(\mathrm{n}=2)$ (Table 3$)$.

Tuberculosis was the most common cause in patients presenting with tamponade $(\mathrm{n}=14 ; 35 \%)$ followed by malignancy $(\mathrm{n}=10 ; 25 \%)$ (Table 4$)$.

The etiology of pericardial effusion was evident clinically and by specific investigation.

55 patients $(87 \%)$ had the correct diagnosis of pericardial effusion and 49 patients had the diagnosis on first visit and remaining patients on subsequent visit.

The arrhythmia associated with pericardial effusion was in 7 patients (11\%) and the most common arrhythmia was AF (Table 5).

Table 1. Showing demographic, clinical and labarotory characteristics.

\begin{tabular}{|c|c|c|}
\hline Clinical/laboratory characteristics & Number & Percentage $(100 \%)$ \\
\hline Total number of patients & 63 & \\
\hline \multirow{2}{*}{ Age range (in years) } & 8 to 88 & \\
\hline & Mean: $42.28 \pm$ SD 22.50 & \\
\hline Females & 26 & 41.27 \\
\hline Males & 37 & 58.73 \\
\hline \multicolumn{3}{|l|}{ Symptoms } \\
\hline Breathlessness & 60 & 95.2 \\
\hline Chest pain & 24 & 38 \\
\hline Fever & 30 & 47.6 \\
\hline Cough & 35 & 55.5 \\
\hline Palpitation & 2 & 3.1 \\
\hline Other symptoms & 21 & 33 \\
\hline Asymptomatic & 2 & 3.1 \\
\hline \multicolumn{3}{|l|}{ Signs } \\
\hline Tachycardia & 40 & 63.4 \\
\hline Bradycardia & 2 & 3.1 \\
\hline Hypotension & 15 & 23.8 \\
\hline Raised JVP & 17 & 26.9 \\
\hline Pulsus paradoxus & 17 & 26.9 \\
\hline Muffled Heart sounds & 23 & 36.5 \\
\hline Electrical Alternans on ECG & 8 & 12 \\
\hline Cardiomegaly on CXR & 56 & 88 \\
\hline \multicolumn{3}{|l|}{ Echocardiography } \\
\hline Moderate PE & 10 & 15.8 \\
\hline Large PE & 53 & 84 \\
\hline Cardiac tamponade (Clinical + Echo) & 40 & 63 \\
\hline
\end{tabular}


Table 2. Showing etiological profile of pericardial effusion.

\begin{tabular}{ccc}
\hline Diagnosis & $\mathbf{n}=\mathbf{6 3}$ & Percentage (100\%) \\
\hline Tubercular (TB) & 23 & 36.5 \\
Malignant & 12 & 19 \\
Idiopathic/Viral & 8 & 12.6 \\
CKD (Uraemia) & 3 & 4.7 \\
CKD with TB & 4 & 6.3 \\
Post MI & 4 & 6.3 \\
Collagen Vascular Disease (SLE) & 3 & 4.7 \\
Hypothyroidism & 4 & 6.3 \\
Pyogenic & 3 & 4.7 \\
Suspected Parasitic Infection & 2 & 3.1 \\
HIV-Infection & 1 & 1.5 \\
\hline
\end{tabular}

Table 3. Pattern of malignancy associated with pericardial effusion.

\begin{tabular}{ccc}
\hline Malignancy & $\mathbf{n = 1 2}$ & Percentage (100\%) \\
\hline Carcinoma Lung & 5 & 41.6 \\
Breast cancer & 1 & 8.3 \\
Lymphoma & 2 & 16.6 \\
Mediastinal Lymphoma & 1 & \\
NHL & 1 & 8.3 \\
Mediastinal Seminoma & 1 & 8.3 \\
Mediastinal germ cell tumour & 1 & 8.3 \\
Peripheral T cell Lymphoma & 1 & 8.3 \\
Multiple myeloma & 1 & \\
\hline
\end{tabular}

Table 4. Number and percentage of patients presenting as tamponade in different etiological groups.

\begin{tabular}{ccc}
\hline Etiology & $\mathbf{n}=\mathbf{4 0}$ & Percentage (100\%) \\
\hline Tuberculosis & 14 & 35 \\
Malignancy & 10 & 25 \\
Idiopathic & 4 & 10 \\
Uraemia & 3 & 7.5 \\
Others & 9 & 22.5 \\
\hline
\end{tabular}

Table 5. Showing different arrhythmia associated with pericardial effusion.

\begin{tabular}{ccc}
\hline Arrhythmia & $\mathbf{n = 7}$ & Percentage (100\%) \\
\hline AF & 3 & 42.8 \\
VPC & 1 & 14.2 \\
PSVT & 1 & 14.2 \\
VT & 1 & 14.2 \\
IVCD & 1 & 14.2 \\
\hline
\end{tabular}


Pericardiocentesis was done in 46 patients (73\%) and the approach was subxiphoid in 44 patients (95.6\%), apical in 2 patients $(4.3 \%)$.

The procedure related complications was in 4 patients which were vasovagal response with transient hypotension, subcutaneous emphysema and supraventricular tachycardia.

There was no death as a consequence of the procedure.

Out of 46 patients who had undergone pericardiocentesis, in 7 patients (11\%) surgical drainage was done due to persistence of effusion.

Pericardectomy was done in 2 patients (3\%), one with purulent effusion and one with chronic constrictive pericarditis.

The total mortality was 12 (19\%). 6 patients (9.5\%) died during hospital stay and 6 patients $(9.5 \%)$ outside the hospital which was confirmed by phone contact on follow up. The underlying etiology of these patients is shown in Figure 1. Among these patients who died, 9 (75\%) had cardiac tamponade and had undergone pericardiocentesis.

The Echo characteristics of the pericardial effusion were helpful to differentiate between the tuberculous, malignant and idiopathic etiologies.

Fibrin strands and thickened fluid were found mainly with tuberculosis where as shaggy pericardium was associated with tuberculous, idiopathic and bacterial etiologies (Tables 6-8, Figure 2).

The diagnosis of tubercular pericardial effusion was done based on clinical and specific investigations.

Among 23 tubercular patients, 18 had the correct diagnosis and the remaining 5 patients were treated empirically with ATT who responded on it.

In total $70 \%$ of tubercular patients had ADA activity $\geq 30 \mathrm{U} / \mathrm{L}$ and $65 \%$ with ADA activity $\geq 40 \mathrm{U} / \mathrm{L}$. The mean ADA level was $51.94 \pm$ SD 38.43. The sensitivity and specificity of ADA for diagnosing tuberculosis is shown in Table 9.

\section{Follow up}

Patients were followed up after 1 month and then 3 monthly for reassessment of pericardial effusion and complications.

55 patients $(87.3 \%)$ were followed up. Among the remaining patients, 3 died during first hospital admission and 5 (8\%) lost to follow up.

Two patients (3\%) had persistence of effusion for more than 3 months and were labelled chronic idiopathic effusion.

Recurrence was present in 7 patents (11\%) and on reassessment some of them were found to have other disease than previously diagnosed disease on first visit. The effusion status at follow up is shown in Figure 3.

Repeated pericardiocentesis was done in 4 patients $(6.3 \%)$ and there was no any complications related to procedure.

Three patients who had recurrence of effusion died on second hospital admission.

Two patients had CP features on first visit, 1 diagnosed with pyopericardium and other with tuberculosis. 
Among them, patient diagnosed with TB had normal echocardiography on follow up and was labeled as transient $\mathrm{CP}$ while the other patient lost to follow up.

One tubercular patient (4.3\%) who was diagnosed with ECP on first visit had persistence of ECP and 2 patients (8.69\%) with tubercular pericardial effusion developed CCP features on follow up (Mean:9.56 months) (Figure 4).

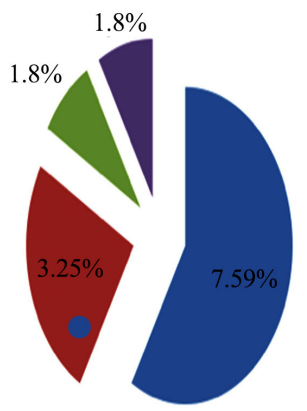

Malignancy

Idiopathic

- Post MI

- HIV

Figure 1. Mortality as per etiology.

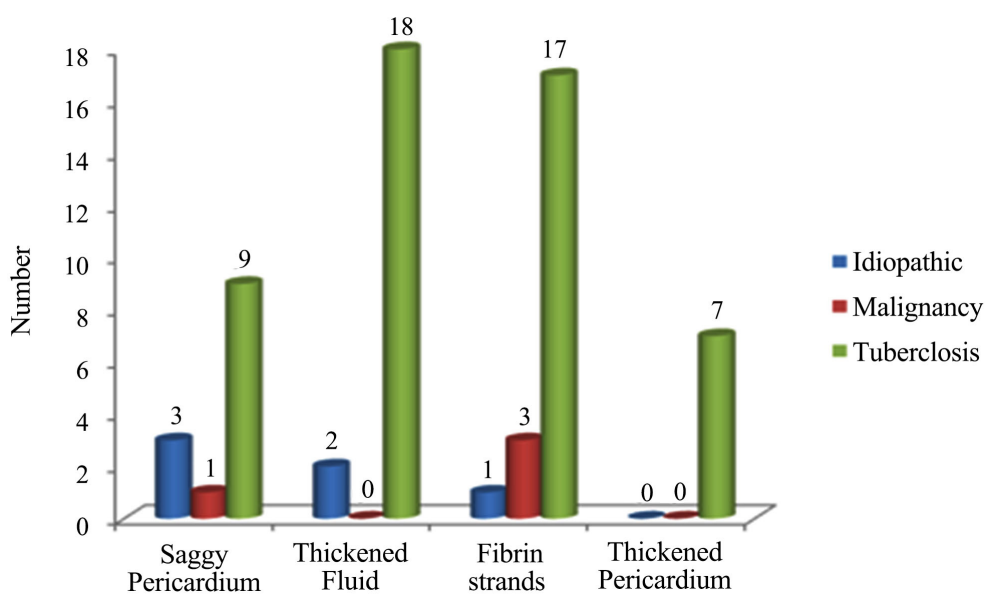

Figure 2. Relationship between etiology and echo findings.

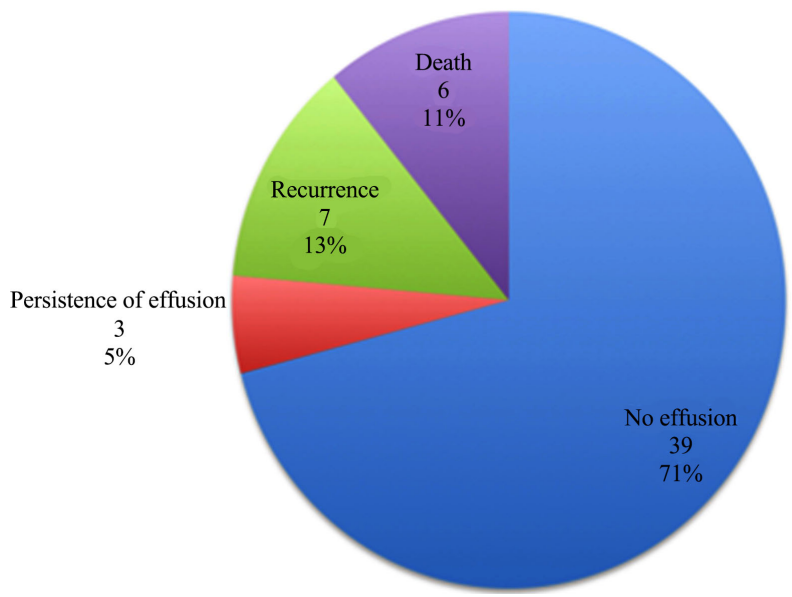

Figure 3. Effusion status at follow up $(n=55)$ (note: during follow up, 6 patients were found to be dead which was confirmed via phone). 


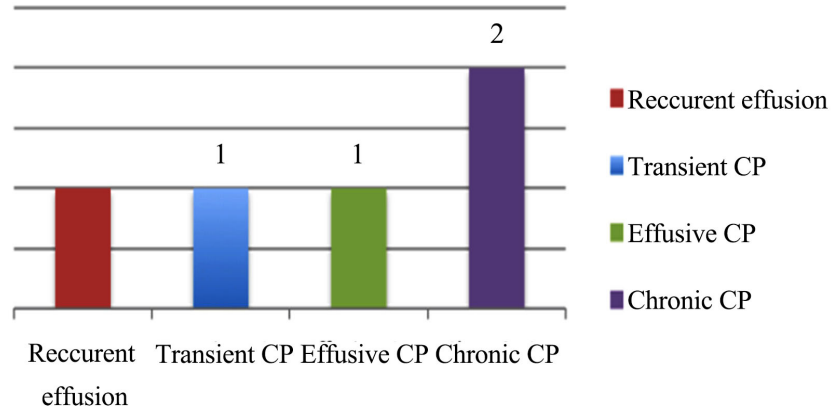

Figure 4. Complications of Tubercular pericardial effusion $(n=5)$.

Table 6. Etiology versus echo characteristics of the effusion.

\begin{tabular}{|c|c|c|c|c|c|c|c|c|}
\hline \multirow[t]{2}{*}{ Etiology } & \multicolumn{2}{|c|}{$\begin{array}{l}\text { Thickened } \\
\text { Pericardium }\end{array}$} & \multicolumn{2}{|c|}{$\begin{array}{c}\text { Thickened } \\
\text { Fluid }\end{array}$} & \multicolumn{2}{|c|}{$\begin{array}{l}\text { Fibrin } \\
\text { Strands }\end{array}$} & \multicolumn{2}{|c|}{$\begin{array}{c}\text { Shaggy } \\
\text { Pericardium }\end{array}$} \\
\hline & No & $\%$ & No & $\%$ & No & $\%$ & No & $\%$ \\
\hline Tuberculous & 7 & 77.7 & 18 & 60 & 17 & 58.6 & 9 & 52.9 \\
\hline Pyogenic & 1 & 11 & 2 & 6.6 & 1 & 3.4 & 1 & 5.8 \\
\hline Malignancy & 0 & 0 & 4 & 13.3 & 3 & 10 & 1 & 5.8 \\
\hline Idiopathic & 1 & 11 & 2 & 6.6 & 1 & 3.4 & 3 & 17.6 \\
\hline CTD & 0 & 0 & 2 & 6.6 & 2 & 6.8 & 1 & 5.8 \\
\hline Uraemic & 0 & 0 & 0 & 0 & 1 & 3.4 & 1 & 5.8 \\
\hline Others & 0 & 0 & 2 & 6.6 & 4 & 13.7 & 1 & 5.8 \\
\hline Total & 9 & 100 & 30 & 100 & 29 & 100 & 17 & 100 \\
\hline
\end{tabular}

Table 7. Relationship between the etiology and the Echo features of the effusion.

\begin{tabular}{|c|c|c|c|c|c|c|c|c|c|}
\hline \multirow{3}{*}{$\begin{array}{l}\text { Echo feature } \\
\text { Fibrin strands }\end{array}$} & \multicolumn{3}{|c|}{ Tuberculous (23) } & \multicolumn{3}{|c|}{ Malignant (12) } & \multicolumn{3}{|c|}{ Idiopathic (8) } \\
\hline & No & $\%$ & $\mathrm{P}$ & No & $\%$ & $\mathrm{P}$ & No & $\%$ & $\mathrm{p}$ \\
\hline & 17 & 73.9 & 0.001 & 3 & 25 & 0.104 & 1 & 12.5 & 0.042 \\
\hline $\begin{array}{l}\text { Thickened } \\
\text { pericardium }\end{array}$ & 7 & 30 & 0.005 & 0 & 0 & & 1 & 12.5 & 0.042 \\
\hline $\begin{array}{c}\text { Thickened } \\
\text { fluid }\end{array}$ & 18 & 78.2 & $<0.001$ & 4 & 33.3 & 0.271 & 2 & 25 & 0.170 \\
\hline $\begin{array}{c}\text { Shaggy } \\
\text { Pericardium }\end{array}$ & 9 & 39 & 0.100 & 1 & 8.3 & 0.106 & 3 & 37.5 & 0.473 \\
\hline
\end{tabular}

Table 8. Diagnostic value of echocardiographic manifestations of tuberculous pericardial effusion.

\begin{tabular}{ccccc}
\hline Echo Feature & Sensitivity & Specificity & $\begin{array}{c}\text { Positive } \\
\text { predictive value }\end{array}$ & $\begin{array}{c}\text { Negative } \\
\text { predicitive value }\end{array}$ \\
\hline $\begin{array}{c}\text { Fibrin Strand } \\
\text { Thickened } \\
\text { fluid/Exudates }\end{array}$ & $74 \%$ & $70 \%$ & $58 \%$ & $82 \%$ \\
$\begin{array}{c}\text { Shaggy pericardium } \\
\text { Thickened }\end{array}$ & $39 \%$ & $80 \%$ & $60 \%$ & $85 \%$ \\
pericardium & $44 \%$ & $95 \%$ & $53 \%$ & $69 \%$ \\
\hline
\end{tabular}


Table 9. Utility of various diagnostic tests for tuberculous pericardial effusion.

\begin{tabular}{cccccc}
\hline Tests & Sensitivity & Specificity & $\begin{array}{c}\text { Positive } \\
\text { predictive } \\
\text { value }\end{array}$ & $\begin{array}{c}\text { Negative } \\
\text { predictive } \\
\text { value }\end{array}$ & p value \\
\hline Pericardial ADA $\geq 30 \mathrm{U} / \mathrm{L}$ & $84 \%$ & $75 \%$ & $69 \%$ & $87 \%$ & $<0.001$ \\
Pericardial ADA $\geq 40 \mathrm{U} / \mathrm{L}$ & $80 \%$ & $83 \%$ & $75 \%$ & $85 \%$ & $<0.001$ \\
Pericardial fluid L/N ratio $\geq 1$ & $50 \%$ & $75 \%$ & $72 \%$ & $54 \%$ & 0.085 \\
Tuberculin skin test $\geq 10 \mathrm{~mm}$ & $30 \%$ & $94 \%$ & $78 \%$ & $67 \%$ & 0.011 \\
\hline
\end{tabular}

\section{Discussion}

Pericardial effusion can occur at any age but age specific etiologies may differ. In our study majority of patients were in age group of 30 to 60 years of age.

The commonest symptoms and signs in our patients were breathlessness and tachycardia.

40 patients in our study had clinical and echo evidence of cardiac tamponade.

Most common ECG findings of our patients were sinus tachycardia, low voltage ECG and nonspecific ST-T wave changes.

In our study the most common cause of pericardial effusion was tuberculosis (36.5\%) followed by malignancy (19\%) and idiopathic/viral (12.6\%).

In the study conducted by Alkhalifa et al. [5] tuberculosis (29.4\%) was the most common etiology followed by malignancy (17.6\%).

Similarly in the study conducted by Jamal Uddin et al. [6] in India, most common etiology was tuberculosis $27.27 \%$ followed by idiopathic $19.69 \%$ then Uremia $16.66 \%$ and Malignant $13.63 \%$.

In developed countries the result is slightly dissimilar. Corey et al. [7] in United States investigated the etiology of pericardial effusion in 57 patients.

The most common diagnosis were malignancy (23\%), viral infection (14\%), radiation induced inflammation (14\%). In another study conducted in Spain general hospital by Sagristà Sauleda et al. [8] the most common diagnosis was Idiopathic (20\%), Neoplastic (13\%), Post MI (8\%) and less common was tubercular (2\%).

The high frequency of tuberculosis from the above studies reflects the high incidence of tuberculosis in the developing countries like Nepal, India.

Acute idiopathic effusion is considered mostly of viral origin. Testing for specific viruses is not routinely done and in our country it is less commonly done because of cost benefit ratio, low yield, unavailability and less impact on management. So in our study the idiopathic effusion was thought mostly due to viral cause.

Among malignant patients in our study the most common malignancy was lung cancer followed by lymphoma.

In the study conducted by Irfan Yaqoob [9] et al. among malignancies, carcinoma lung was the most common followed by breast carcinoma and lymphoma.

In our study there was a strong positive correlation between thickened appearance of fluid and tuberculosis ( $78 \%$ sensitivity and $70 \%$ specificity). 
In the study conducted by Alkhalifa et al. [5] there was a strong positive correlation between the thickened appearance of the fluid and tuberculous etiology $(\mathrm{p}<0.001)$.

The fibrin strands and thickened pericardium in our study was strongly correlated with tuberculosis ( $74 \%$ sensitivity, $70 \%$ specificity) and (44\% sensitivity, $95 \%$ specificity)respectively.

In the study conducted by Alkhalifa et al. [5] fibrin strands was found to be strongly correlated with tuberculosis $(\mathrm{p}<0.001)$

Liu and colleagues [10] demonstrated that thickened pericardium and fibrin strands were highly specific (94\% and $88 \%$, respectively) and exudative coating had a high sensitivity (100\%) but low specificity $(22 \%)$ in the diagnosis of tuberculous pericarditis.

The pericardial fluid ADA was significantly elevated in tuberculous pericardial effusion in our study.

The diagnostic results were obtained at cut off value of ADA $\geq 30 \mathrm{U} / \mathrm{L}(84 \%$ sensitivity and $75 \%$ specificity) and ADA $\geq 40 \mathrm{U} / \mathrm{L}$ (80\% sensitivity and $83 \%$ specificity).

In the study conducted by Burgess LJ et al. [11] pericardial ADA levels $\geq 30$ $\mathrm{U} / \mathrm{L}$ had sensitivity and specificity of $94 \%$ and $68 \%$ respectively.

In the study conducted by $\mathrm{H}$ Reuter et al. [12] the pericardial ADA level $\geq 40$ had sensitivity and specificity of $87 \%$ and $89 \%$ respectively.

The use of ADA level in patients with clinical suspicious of tuberculosis provides a rapid and accurate means of diagnosing tuberculosis especially in high prevalence areas.

Urgent pericardiocentesis should be done in patients with tamponade which may prove life saving.

In our study pericardioccentesis was done in 46 patients (73\%). There was no mortality associated with pericardiocentesis and the procedure related complications was in 4 patients (6\%).

This was similar to the study conducted by Tsang TS et al. [13] where the procedural success rate was $98 \%$ and the overall complications rate was $4.7 \%$.

In our study patients were followed up for one year. 2 patients (3\%) with unknown cause were labelled as chronic idiopathic effusion.

In the study conducted by Irfan Yaqoob et al. [9] six patients (5.8\%) had significant effusion of more than three months duration in whom no cause could be established.

Two patients (8\%) with tuberculosis developed features of CP on follow up and was diagnosed as CCP.

1 patient (4\%) with features of ECP on first visit had persistence of ECP features on subsequent visits.

The mean follow up of these patients was 9.56 months.

In the study conducted by S George et al. [14], 2 tubercular patients (7.4\%) presented with ECP on first visit, 2 tubercular patients (7.4\%) developed CCP on 
follow up (mean 11 months).

2 patients in our study who presented with large pericardial effusion had history of ingestion of crab and found to have high blood and fluid eosinophilia with exclusion of other causes. It was thought to be probably due to parasitic infestation likely due to paragonimus and was given antihelminthics. These patients responded with the drugs and had no effusion on follow up visit.

\section{Limitation of the Study}

The present study had some limitations that need to be considered. The present study did not determine the direct evidence for diagnosis of viral and tuberculous pericardial effusion.

The study could not focus on the pericardial biopsy results for determining different etiology due to less number of patients.

Due to small sample size and short duration of follow up, less number of patients with development of constrictive pericarditis and other complications were detected.

So a long follow up is necessary to compare the results with those of other developing and developed countries.

\section{Conclusions}

From this study we observed the various presenting features for pericardial effusion and cardiac tamponade.

The common etiology in our study was tuberculosis followed by malignancy and idiopathic.

The idiopathic pericardial effusion should be diagnosed only after a thorough evaluation of possible underlying causes.

Urgent pericardiocentesis should be done whenever there is actual or threatened tamponade and may prove life saving.

Purulent pericardial effusion should also be drained even in absence of tamponade. The echocardiography can help in revealing the undiagnosed patients and add up useful information regarding the etiology.

Although small sample size, there was significant echo correlation for different etiology in our study.

The fibrin strand, thickened appearance of fluid and shaggy pericardium were helpful in differentiating tuberculosis from malignancy and idiopathic.

\section{Conflicts of Interest}

The authors declare no conflicts of interest regarding the publication of this paper.

\section{References}

[1] Grogan, M. (2017) Pericardial Effusion: What Are the Symptoms? https://www.mayoclinic.org/diseases-conditions/pericardial-effusion/symptoms-ca uses/syc-20353720 
[2] Chang, S. and Maharaj, S. (2014) Brief Images: Massive Pericardial Effusion. Images in Paediatric Cardiology, 16, Article ID: PMC4521324.

[3] Strimel, W.J., Ayub, B., et al. (2018) Pericardial Effusion. https://emedicine.medscape.com/article/157325-overview

[4] Klein, A.L., Abbara, S., Agler, D.A., Appleton, C.P., Asher, C.R., Hoit, B., et al. (2013) American Society of Echocardiography Clinical Recommendations for Multimodality Cardiovascular Imaging of Patients with Pericardial Disease: Endorsed by the Society for Cardiovascular Magnetic Resonance and Society of Cardiovascular Computed Tomography. Journal of the American Society of Echocardiography, 26, 965-1012. https://doi.org/10.1016/j.echo.2013.06.023

[5] Alkhalifa, M.S., Elnima, M. and Ismaeel, S.A. (2019) Echocardiography in Helping to Determine the Causes of Pericardial Effusion in the Sudanese Patients. Sudan Journal of Medical Sciences, 4, 63-69. https://doi.org/10.4314/sjms.v4i1.44882

[6] Uddin, M.J., Singh, M.P. and Mehdi, M.D. (2016) Study of Etiological and Clinical Profile of Pericardial Effusion in a Tertiary Care Hospital in Kosi Region of Bihar, International Journal of Advances in Medicine, 3, 514-518.

https://doi.org/10.18203/2349-3933.ijam20161844

[7] Corey, G.R., Campbell, P.T., Van Trigt, P., Kenney, R.T., O’Connor, C.M., Sheikh, K.H., et al. (1993) Etiology of Large Pericardial Effusions. The American Journal of Medicine, 95, 209-213. https://doi.org/10.1016/0002-9343(93)90262-N

[8] Sagrista-Sauleda, J., Merce, J., Permanyer-Miralaa, G. and Soler-Soler, J. (2000) Clinical Clues to the Causes of Large Pericardial Effusions. The American Journal of Medicine, 109, 95-101. https://doi.org/10.1016/S0002-9343(00)00459-9

[9] Yaqoob, I., Khan, K.A., Beig, J.R., Bhat, I.A., Tramboo, N.A., Hafeez, I., et al. (2016) Etiological Profile of Pericardial Effusion in Kashmir: A Study from Northern India. International Invention Journal of Medicine and Medical Sciences, 3, 1-5.

[10] Liu, P.Y., Li, Y.H., Tsai, W.C., Tsai, L.M., Chao, T.H., Yung, Y.J., et al. (2001) Usefulness of Echocardiographic Intrapericardial Abnormalities in the Diagnosis of Tuberculous Pericardial Effusion. The American Journal of Cardiology, 87, 1133-1135. https://doi.org/10.1016/S0002-9149(01)01481-3

[11] Burgess, L.J., Reuter, H., Carstens, M.E., Frans, J.J., et al. (2002) The Use of Adenosine Deaminase and Interferon- $\gamma$ as Diagnostic Tools for Tuberculous Pericarditis. CHEST, 122, 900-905. https://doi.org/10.1378/chest.122.3.900

[12] Reuter, H., Burgess, L., van Vuuren, W. and Doubell, A. (2006) Diagnosing Tuberculous Pericarditis. QJM: An International Journal of Medicine, 99, 827-839. https://doi.org/10.1093/qjmed/hcl123

[13] Tsang, T.S., Enriquez-Sarano, M., Freeman, W.K., Barnes, M.E., Sinak, L.J., Gersh, B.J., et al. (2002) Consecutive 1127 Therapeutic Echocardiographicaly Pericardiocentesis: Clinical Profile, Practice Patterns, and Outcomes Spanning 21 Years. Mayo Clinic Proceedings, 77, 429-436. https://doi.org/10.1016/S0025-6196(11)62211-8

[14] George, S., Salama, A.L., Uthaman, B. and Cherian, G. (2004) Echocardiography in Differentiating Tuberculous from Chronic Idiopathic Pericardial Effusion. Heart, 90, 1338-1339. https://doi.org/10.1136/hrt.2003.020081 